EPJ Web of Conferences 92,02117 (2015)

DOI: $10.1051 /$ epjconf/20159202117

(C) Owned by the authors, published by EDP Sciences, 2015

\title{
Flow structure in front of the broad-crested weir
}

\author{
Zbyněk Zachoval ${ }^{1, a}$ and Ladislav Roušar ${ }^{2}$ \\ ${ }^{1} B U T, F C E$, IWS, LWMR, 60200 Brno, Czech Republic \\ ${ }^{2} B U T, F C E$, IWS, 60200 Brno, Czech Republic
}

\begin{abstract}
The paper deals with research focused on description of flow structure in front of broad-crested weir. Based on experimental measurement, the flow structure in front of the weir (the recirculation zone of flow and tornado vortices) and flow structure on the weir crest has been described. The determined flow character has been simulated using numerical model and based on comparing results the suitable model of turbulence has been recommended.
\end{abstract}

\section{Introduction}

Rectangular broad-crested weirs are frequently used for the determination of discharge [1]. Weirs are mounted in a prismatic rectangular channel usually the same width $B$ as width of weir $b$ to sufficiently increase water surface, neverthless, do not influence on maximum capacity of channel. The weir crest is horizontal with the weir thickness $t$, the upstream and downstream faces are vertical, the weir surface is smooth, the upstream and downstream weir edges are sharp and the weir height is $P$ (Figure 1). The effort for mounting them is to ensure a free overflow in whole a range of measuring discharges [2].

Rectangular broad-crested weirs form three recirculation zones of flow [3]: upstream [4], crest [5] and downstream recirculation zones [3] (Figure 1). The upstream and crest recirculation zones have an influence on a weir capacity, the downstream recirculation zone does not because the parallel supercritical flow is created on the weir crest [6].

\section{Flow structure in front of the broad- crested weir}

At different relative weir heights $h / P$, a different flow structure forms in front of upstream face [7]. In a case of high weirs, the upstream recirculation zone is not formed; in medium-high weirs, only the upstream recirculation zone is formed; and in low weirs, the upstream recirculation zone is formed and is supplemented by tornado vortices [8-11]. The criteria for the formation of individual flow structures have been determined by Zachoval and Roušar [12].

\footnotetext{
a Corresponding author: zachoval.z@fce.vutbr.cz
}

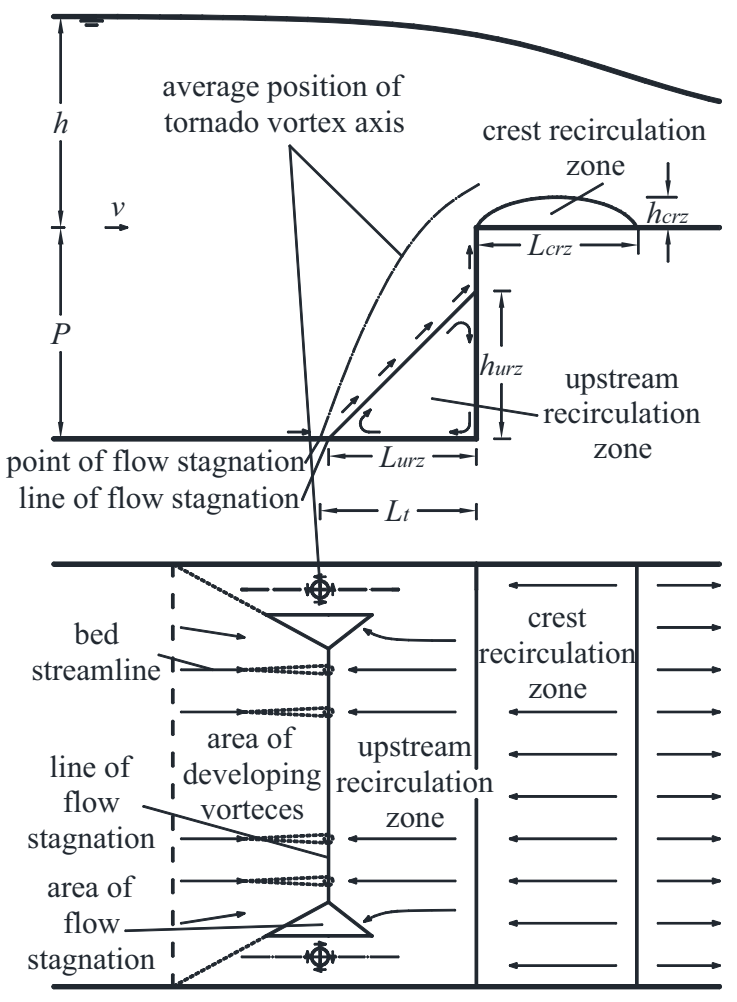

Figure 1. Scheme of weir, flow and notation of variables.

\section{Review of numerical models of flow over broad-crested weir}

The numerical modelling of potential flow over broadcrested weir was investigated by, e.g., Moos [13], Streetharan [14], Dias et al. [15]. However, the potential flow does not describe recirculation zones of flow, hence the results were different. To achieve reliable results of 
transit flow, they must have been composed by special ways [13].

The simulation of vortical flow over rectangular weir was studied by Bombardeli et al. [16]. They used 2D model for turbulent flow of incompressible viscous liquid. The flow was described by Reynolds-averaged Navier-Stokes equations (RANS). Turbulence was solved by Renormalized Group (RNG) $k-\varepsilon$ model [17]. They compared results with measurements Hager and Schwalt [18] and stated good agreement with a pattern of water surface even in range of the crest recirculation zone. Shaker and Rhodes [19] simulated two phase flow in 3D described by RANS equations supplemented with $k-\varepsilon$ turbulence model [20] and wall function. To determine water surface they used Volume of fluid (VOF) method [21]. They found good agreement with flow and water surface level, only they noted differences in position of the crest recirculation zone and in postition of a nappe. Hargeaves et al. [22] simulated two phase 2D flow (one case 3D) and tested three different turbulence models $k-\varepsilon$, RNG $k-\varepsilon$ and Reynolds Stress Model (RSM) [23]. RNG $k-\varepsilon$ and RSM turbulence models simulated flow more reliable than $k-\varepsilon$. They determined that $3 \mathrm{D}$ model does not provide in comparison with $2 \mathrm{D}$ model a improvement in pattern of water surface. The greatest difficulties they saw in simulation of hydraulic jump and areation of flow. Hsu and Ozdemir [24] modeled the same flow as Hargreaves and concentrated on comparison with RNG $k-\varepsilon$ and RSM turbulence models. They stated that model RSM yields better results for water surface level. Kirkgoz et al. [11] dealt with 2D modelling. They compared numerically solved potential flow field, numerically solved flow field with the use of RANS equations and $k-\omega$ [25] and $k-\varepsilon$ tubulence models with measured by method Particle Image Velocimetry (PIV) [26]. They recommended RANS approach with $k-\omega$ turbulence model. Adegbulugbe [27] caried out a study of the related verification as Hargreaves et al. [22]. He claimed that the most accurate results were obtained using with RNG $k-\varepsilon$ turbulence model.

\section{Experiment}

For comparing was chosen the weir described by Zachoval et al. [29]. The weir was made of organic glass, was mounted into a rectangular flume, with weir height $P=0.250 \mathrm{~m}$, width $b=1.003 \mathrm{~m}$ and thickness $t=0.500 \mathrm{~m}$. The velocity field measurements was conducted with a combination of Ultrasonic Velocity Profile (UVP) Monitor and PIV. The velocity field was measured at inlet channel by UVP Monitor [29] and in front of the weir and on the weir crest by PIV [5]. The shape of recirculation zones was visualizated by dye and by particles added into flow. Thereafter, the flow structure was displayed by particles moving on the bottom. The level of water surface was measured by a point gauge and the discharge was determined by calibrated triangular sharp-crested weir.

\section{Numerical model}

\subsection{Selected approach}

The variety of approaches may be used for solving flow structure in front of the rectangular broad-crested weir. Every approach brings with it a certain degree of simplification and, thereby error description compared with reality. The requirements for the results determine the choice of temporal and spatial schematization.

For solving steady overflow from a macroscopic view described by pattern of water surface and by timeaveraged velocity field the models were used based on RANS equations and Large eddy simulation (LES) model with Smagorinsky subgrid-scale (SGS) model. The modelling of recirculation zones not affected side walls was performed by $2 \mathrm{D}$ and tornado vortex by $3 \mathrm{D}$ due to their spatial character. For modelling turbulence with RANS approach the first order models were selected based on turbulence viscosity: one layer models Standard $k-\varepsilon$, RNG $k-\varepsilon$, Standard $k-\omega$ models and two layer Shear Stress Transport (SST) model [28]. Further, the second order models were used based on Reynolds stress transport equation [23]: Baseline (BSL) Reynolds Stress (RS) and Speziale-Sarkar-Gatski (SSG) RS [30]. For solving the software were used ANSYS-CFX (3D, 2D) (Figure 2) - two phase flow, ANSYS-Flotran (2D) (Figure 3) - one phase flow and Flow-3D (2D) (Figure 4) - one phase flow.

\subsection{Calculation}

Fluid domain geometry included the inlet channel, the weir and a part of outlet channel with free nappe. The inlet channel length was so long to develop velocity profile.

At inlet boundary the hydrostatic pressure distribution was set for a depth established from the measurements and a constant velocity. At outlet boundary the free outflow was set. The walls were hydraulically smooth. The half domain was solved because longitudinal symmetry. The reference pressure was zero.

The number of elements depended on used software and dimension, for 2D model it was approximately from $1 \cdot 10^{5}$ (Flow-3D, ANSYS-Flotran) to $5 \cdot 10^{5}$ (ANSYS$\mathrm{CFX}$ ) and for 3D model $5 \cdot 10^{6}$. The calculations were performed in range of discharges $0.040 \mathrm{~m}^{3} / \mathrm{s}, 0.070 \mathrm{~m}^{3} / \mathrm{s}$ and $0.130 \mathrm{~m}^{3} / \mathrm{s}$. Material properties of water were: density $998 \mathrm{~kg} / \mathrm{m}^{3}$ and viscosity $1 \cdot 10^{-6} \mathrm{~m}^{2} / \mathrm{s}$. All coefficients of turbulence models were left unchanged. The mesh was structured with rectangular elements.

\subsection{Evaluated parameters}

The evaluated parameters were the overflow head $h$ at a given discharge, the length of crest recirculation zone $L_{c r z}$, the height of crest recirculation zone $h_{c r z}$, the length of upstream recirculation zone $L_{u r z}$, the height of upstream recirculation zone $h_{u r z}$ and the average position of tornado vortex axis $L_{t}$. 


\section{Results}

The measured values of evaluated parameters calculated for the discharge $0.070 \mathrm{~m}^{3} / \mathrm{s}$ are shown in Table 1 .

The results $2 \mathrm{D}$ calculations are presented in the form of velocity fields for all evaluated discharges solved by all software.

Table 1. Evaluated parameters [units in m], $2 \mathrm{D}, Q=0.070 \mathrm{~m}^{3} / \mathrm{s}$.

\begin{tabular}{|c|c|c|c|c|c|}
\hline Model & $h$ & $L_{c r z}$ & $\boldsymbol{h}_{c r z}$ & $L_{u r z}$ & $\boldsymbol{h}_{\text {urz }}$ \\
\hline Measured & 0.131 & 0.108 & 0.022 & 0.140 & 0.140 \\
\hline $\begin{array}{c}\text { Standard } \boldsymbol{k}-\boldsymbol{\varepsilon} \\
\text { ANSYS-Flotran } \\
\text { ANSYS-CFX } \\
\text { Flow-3D } \\
\end{array}$ & $\begin{array}{l}0.132 \\
0.129 \\
0.129 \\
\end{array}$ & $\begin{array}{l}0.050 \\
0.100 \\
0.087 \\
\end{array}$ & $\begin{array}{l}0.006 \\
0.019 \\
0.013 \\
\end{array}$ & $\begin{array}{l}0.087 \\
0.142 \\
0.198 \\
\end{array}$ & $\begin{array}{l}0.067 \\
0.075 \\
0.103 \\
\end{array}$ \\
\hline $\begin{array}{c}\text { RNG } \boldsymbol{k}-\boldsymbol{\varepsilon} \\
\text { ANSYS-Flotran } \\
\text { ANSYS-CFX } \\
\text { Flow-3D } \\
\end{array}$ & & & & & $\begin{array}{l}0.060 \\
0.106 \\
0.084 \\
\end{array}$ \\
\hline $\begin{array}{c}\text { Standard } \boldsymbol{k}-\boldsymbol{\omega} \\
\text { ANSYS-Flotran } \\
\text { ANSYS-CFX } \\
\end{array}$ & $\begin{array}{l}0.129 \\
0.132 \\
\end{array}$ & $\begin{array}{l}0.057 \\
0.069 \\
\end{array}$ & $\begin{array}{l}0.006 \\
0.011 \\
\end{array}$ & & $\begin{array}{l}0.061 \\
0.111\end{array}$ \\
\hline $\begin{array}{c}\text { SST } \\
\text { ANSYS-Flotran } \\
\text { ANSYS-CFX } \\
\end{array}$ & $\begin{array}{l}0.128 \\
0.130 \\
\end{array}$ & $\begin{array}{l}0.074 \\
0.114 \\
\end{array}$ & $\begin{array}{l}0.015 \\
0.020 \\
\end{array}$ & $\begin{array}{l}0.360 \\
0.162\end{array}$ & $\begin{array}{l}0.113 \\
0.111\end{array}$ \\
\hline $\begin{array}{c}\text { BSL RS } \\
\text { ANSYS-CFX } \\
\end{array}$ & 0.129 & 0.123 & 0.020 & 0.197 & 0.128 \\
\hline $\begin{array}{c}\text { SSG RS } \\
\text { ANSYS-CFX } \\
\end{array}$ & 0.129 & 0.143 & 0.021 & 0.230 & 0.114 \\
\hline $\begin{array}{c}\text { LES } \\
\text { (Smagorinsky SGS) } \\
\text { Flow-3D }\end{array}$ & 0.128 & 0.092 & 0.015 & 0.317 & 0.116 \\
\hline
\end{tabular}

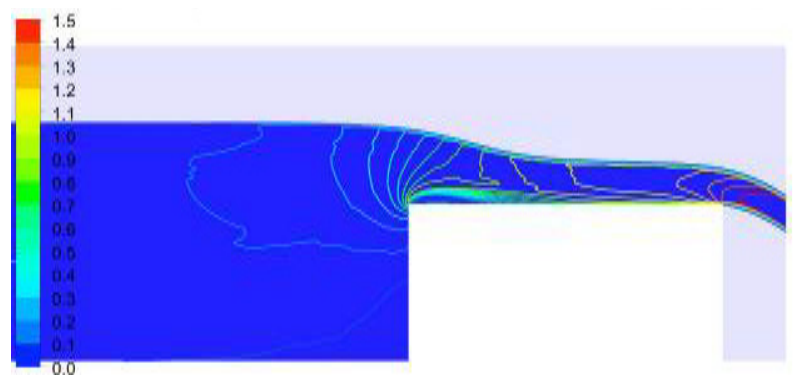

Figure 2. ANSYS-CFX, 2D, $k-\varepsilon, 0.070 \mathrm{~m}^{3} / \mathrm{s}$, velocity field.

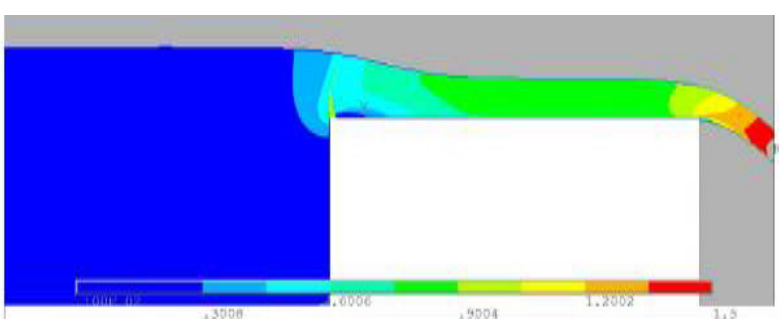

Figure 3. ANSYS-Flotran, 2D, $k-\varepsilon, 0.040 \mathrm{~m}^{3} / \mathrm{s}$, velocity field.

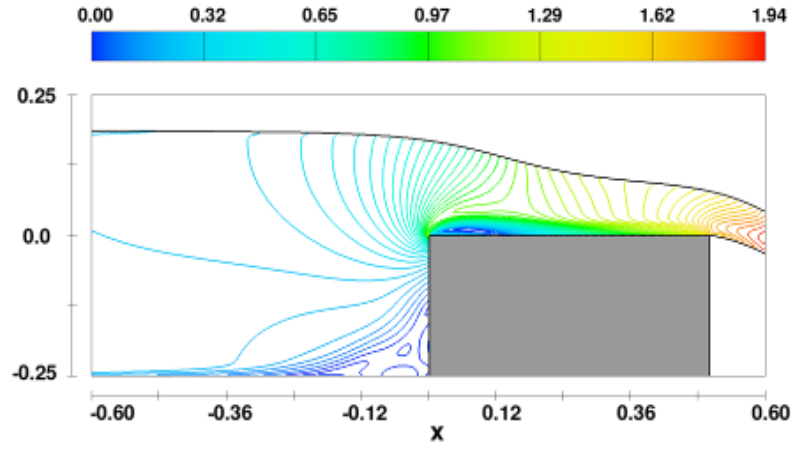

Figure 4. Flow-3D, 2D, $k-\varepsilon, 0.130 \mathrm{~m}^{3} / \mathrm{s}$, velocity field.

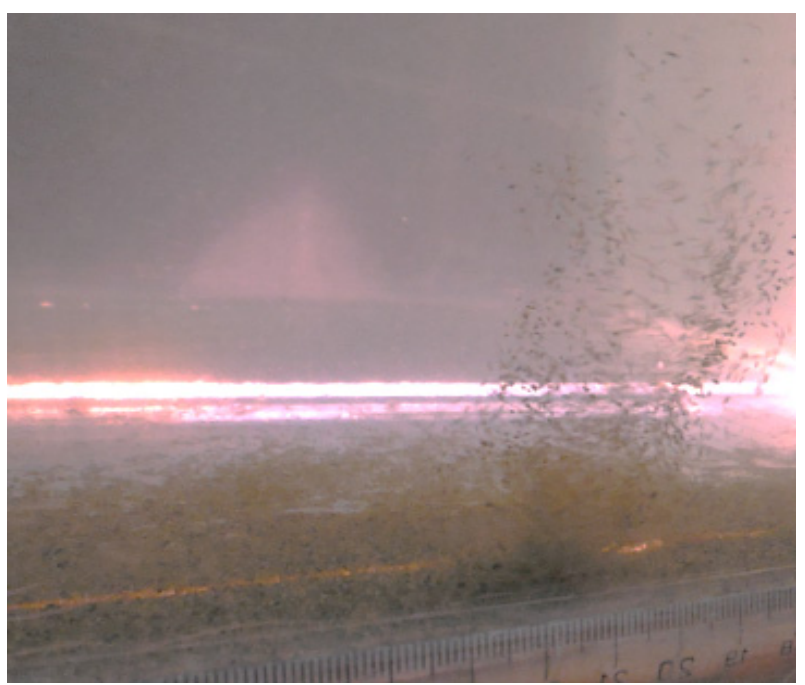

Figure 5. Tornado vortex.

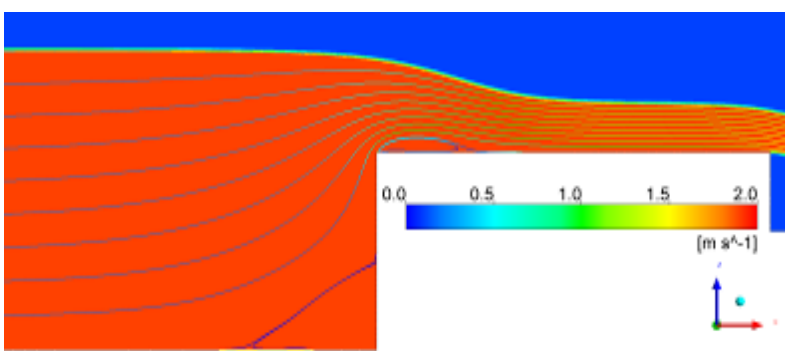

Figure 6. ANSYS-CFX, 2D, SST, $0.070 \mathrm{~m}^{3} / \mathrm{s}$, streamlines.

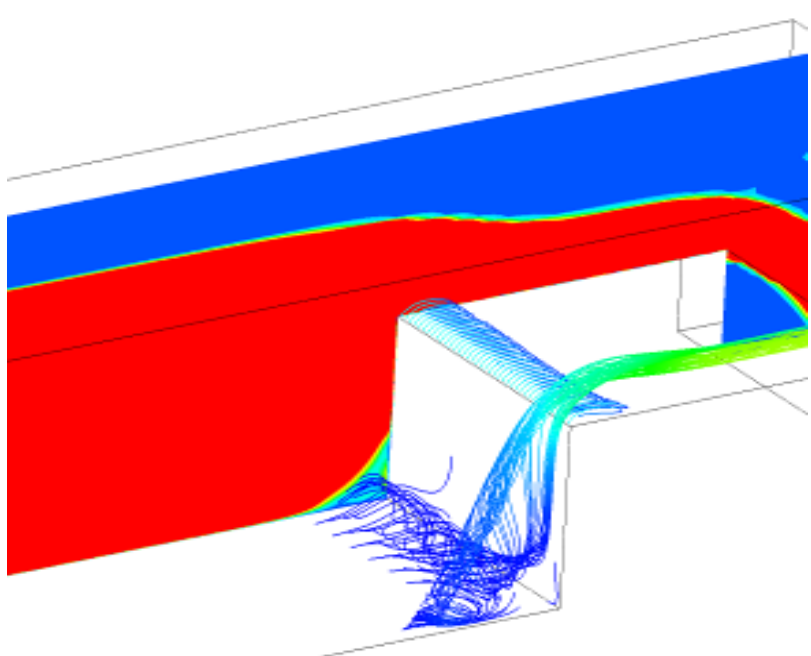

Figure 7. ANSYS-CFX, 3D, SST, $0.070 \mathrm{~m}^{3} / \mathrm{s}$. 


\section{Conclusions}

From the results in Table 1 is evident that values of evaluated parameters change with used software and turbulence model.

Practically, all one layer models based on turbulent viscosity underestimate a size of recirculation zones. The most reliable results of them RNG $k-\varepsilon$ turbulence model provide. The models based on Reynolds stress transport equation overestimate the length of recirculation zones in direction of flow. Two layers model SST provides the most reliable results from all used models (Figure 6). LES model overestimates the length of upstream recirculation zone. Overestimation of the length of upstream recirculation zone may be caused by a fact that the numerical model due to small number of elements does not simulate vortices arising near the bed in front of the upstream recirculation zone [12].

The values of results in Table 1 are significantly dependent on the element size which it is mainly reflected at the height of crest recirculation zone. The best results are achieved with the largest number of elements which explains the differences in results with used software.

The solved overflow head was practically for all models slightly smaller than measured. Error of its determination is in all cases up to $3 \%$. The correct modelling of the height of the crest recirculation zone is essential to determinate the overflow head. Therefore, it is recommended to use at least 8 elements along its height. In the case of using a smaller number of elements the modelled crest recirculation zone is smaller. In the case of using a larger number of elements having no significant refinement its height. The correct modelling of the upstream recirculation zone has significantly less an influence on the overflow head than the crest recirculation zone.

Tornado vortex (Figure 5) was able to simulate (Figure 7), its position is in a range of measured values [12]. The flow in area of tornado vortex is developed during the simulation process as the last. Therefore, the sufficient number of simulation is necessary to perform. For determining of the overflow head has negligible effect.

For practical use in determining of the overflow head at known discharge and vice versa is possible due to the relatively small demands on mesh and high accuracy determination of flow character to recommend RANS approach and a two layer SST turbulence model.

\section{Acknowledgments}

Acknowledgments are due to projects FAST-S-14-2203 Characteristics of submergence of low rectangular broadcrested weirs and FAST-S-13-2010 Transport of particles over the rectangular broad-crested weir.

\section{References}

1. ISO 3846 (2008)

2. M. G. Bos, Discharge measurement structures. (ILRI, Wageningen, 1989)

3. W. H. Hager, Discharge measurement structures. (EPFL, Lausanne, 1986)
4. S. Muller, P. Guiraud, A. Line, J. Hydraul. Res., 49, 2 (2011)

5. Z. Zachoval, I. Mistrová, L. Roušar, J. Šulc, P. Zubík, J. Hydrol. Hydromech., 60, 4, 288-298 (2012)

6. Z. Zachoval, M. Knéblová, L. Roušar, J. Rumann, J. Sulc, J. Hydrol. Hydromech., 62, 2, 145-149 (2014)

7. Z. Zachoval, P. Zubík, I. Mistrová, L. Roušar, Experimentálni výzkum a numerické modelováni úplavu za návodni hranou přelivu se širokou korunou obdélníkového průřezu. (BUT, Brno, 2012)

8. N. Rajaratnam, D. Muralidhar, J. Hydraul. Res., 9, 2 (1971)

9. O. Baud, W. H. Hager, J. Envi. Eng., 126, 2 (2000)

10. C. A. Gonzalez, H. Chanson, Flow Meas. Inst., 18 (2007)

11. M. S. Kirkgoz, M. S. Akoz, A. A., Oner, Canadian J. Civil Eng., 35, 9, 975-986 (2008)

12. Z. Zachoval, L. Roušar, Transport dnových splavenin přes přeliv pravoúhlého prưřezu se širokou korunou. (BUT, Brno, 2014)

13. Moss, W. D., J. Fluid Mech., 52, 2, 307-320 (1972)

14. P. M. Sreetharan, Analytical and experimental investigation of flow measurement by long-based weirs in the rectilinear and curvilinear ranges. (The Hatfield Polytechnic, Hatfield 1983)

15. F. Dias, J. B. Keller, J.-M. Vanden-Broeck, Phys. Fluids, 31, 8, 2071-2076 (1988)

16. F. A. Bombardeli, M. H. García, M. E. Caisley. HydroInformatics 4th (2000)

17. V. Yakhot, S. A. Orszag, Phys. Review Letters, 57, 14 (1986)

18. W. H. Hager, M., J. Schwalt, Irrig. Drainage Eng. 120, 1, 13-26 (1994)

19. M. A. Sarker, D. G. Rhodes, Flow Meas. Instrument., 15, 4, 215-219, (2004)

20. B. E. Launder, D. B. Spalding, Computer Methods Appl. Mech. Eng., 3, 2, 269-289 (1974)

21. C. W. Hirt, B. D. Nichols, J. Comp. Phys. 39 (1981)

22. D. M. Hargreaves, H. P. Morvan, N. G. Wright, Eng. Appl. Comp. Fluid Mech., 1, 2, 136-146. (2007)

23. B. E. Launder, G. J. Reece, W. Rodi, J. Fluid Mech., 68, 3, (1975)

24. T. Hsu, E. C. Ozdemir, Study of complex flows through SFWMD culvert structures by CFD modeling. University of Florida (2007)

25. D. C. Wilcox, AIAA J., 26, 11, 1299-1310 (1988)

26. R. J. Adrian, Annual Rev. Fluid Mech., 23, 261-304 (1991)

27. A. O. Adegbulugbe, A computational fluid dynamic validation study for the prediction and analysis of free surface flow over a broad crested weir. (The University of Leeds, Leeds, 2010)

28. F. R. Menter, Two-Equation Eddy-Viscosity Turbulence Models for Engineering Applications (NASA, 1992)

29. Z. Zachoval, J. Pařílková, L. Roušar, 26th Symposium on Anemometry, Inst. Hydromech. ASCR, Litice, 113-119 (2012)

30. C. G. Speziale, S. Sarkar, T. B. Gatski, Modeling the presure-strain correlation of turbulence - an invariant dynamical systems approach (NASA, 1990) 